\title{
Estratégias de ensino e aprendizagem no Ensino Superior: possibilidades para o curso de Pedagogia
}

\author{
Strategies of teaching and learning in University Education: \\ possibilities for the Pedagogy course
}

\section{Estrategias de enseñanza y aprendizaje en Educación Universitaria: posibilidades para el curso de Pedagogía}

Leidelaine Sérgio Perucci ${ }^{1}$; Elaine Gonçalo Bento ${ }^{2}$

\section{RESUMO}

A temática de ensino e aprendizagem alcança patamares para além da Educação Básica e dos ambientes escolarizados. Este artigo foi produzido a partir da disciplina de Estratégias de Ensino e Aprendizagem oferecida no formato de Mobilidade Internacional Virtual pela Universidad Nacional Costa Rica (UNA-CR) em parceria com o Programa de Pós-graduação em Educação Matemática da Universidade Federal de Ouro Preto (PPGEDMAT/UFOP). Aqui apresentamos uma análise da disciplina de Introdução à Educação do curso de Pedagogia da UFOP em um estudo qualitativo que contemplou a pesquisa bibliográfica e documental, procurou estabelecer pontes com dados históricos do curso e fundamentar essas interlocuções na literatura específica da área de formação de professores, nos documentos legais e na Matriz curricular. Os resultados foram analisados a luz da teoria cientifica a partir de autores como Anastasiou e Alves (2012), Beraza (2011), Freire (1996), Santos (2008) e Libâneo (2002 e 2017). Percebe-se que as estratégias são essenciais no processo educacional e que para cada disciplina e turma há contextos diferentes nas quais as estratégias precisam ser pensadas de forma linear.

Palavras-chave: Pedagogia; Ensino Superior; Educação; Estratégias de Ensino e Aprendizagem.

\begin{abstract}
The teaching and learning theme reaches levels beyond Basic Education and school environments. This article was produced from the Teaching and Learning Strategies course offered in the Virtual International Mobility format by the Universidad Nacional Costa Rica (UNA-CR) in partnership with the Postgraduate Program in Mathematics Education at the Federal University of Ouro Preto (PPGEDMAT / UFOP). Here we present an analysis of the discipline of Introduction to Education in the Pedagogy course at UFOP in a qualitative study that included bibliographic and documentary research, sought to establish bridges with historical data of the course and to base these interlocutions in the specific literature of the area of teacher education, in the legal documents and in the curriculum matrix. The results were analyzed in the light of scientific theory from authors such as Anastasiou and Alves (2012), Beraza (2011), Freire (1996), Santos (2008) and Libâneo (2002 and 2017). It is noticed that strategies are essential in the educational process and that for each discipline and class there are different contexts in which the strategies need to be thought in a linear way.
\end{abstract}

Keywords: Pedagogy; University Education; Education; teaching and learning.

\footnotetext{
${ }^{1}$ Mestranda em Educação pelo Programa de Pós-graduação em Educação da Universidade Federal de Ouro Preto (UFOP), Ouro Preto, MG - Brasil. E-mail: leideperucci@gmail.com

${ }^{2}$ Mestranda em Educação pelo Programa de Pós-graduação em Educação da Universidade Federal de Ouro Preto (UFOP), Ouro Preto, MG - Brasil. E-mail: elainebento2814@gmail.com
} 


\section{RESUMEN}

El tema de la enseñanza y el aprendizaje alcanza niveles más allá de la Educación Básica y los entornos escolares. Este artículo fue elaborado a partir del curso de Estrategias de Enseñanza y Aprendizaje ofrecido en el formato de Movilidad Virtual Internacional por la Universidad Nacional Costa Rica (UNA-CR) en alianza con el Programa de Posgrado en Educación Matemática de la Universidad Federal de Ouro Preto (PPGEDMAT/UFOP). A continuación, presentamos un análisis de la disciplina de Introducción a la Educación en el curso de Pedagogía de la UFOP en un estudio cualitativo que incluyó investigación bibliográfica y documental, buscó establecer puentes con datos históricos del curso y basar estas interlocuciones en la literatura específica del área de formación docente, en los documentos legales y en la matriz curricular. Los resultados se analizaron a la luz de la teoría científica de autores como Anastasiou y Alves (2012), Beraza (2011), Freire (1996), Santos (2008) y Libâneo (2002 y 2017). Se advierte que las estrategias son fundamentales en el proceso educativo y que para cada disciplina y clase existen diferentes contextos en los que es necesario pensar las estrategias de manera lineal.

Palabras clave:

Palabras clave: Pedagogía; Educación universitaria; Educación; Estrategias de enseñanza y aprendizaje.

\section{INTRODUÇÃO}

Pensar a Pedagogia no contexto universitário envolve diversas questões das quais nascem no conceito mais básico "do que é a Pedagogia" que podemos considerar, de maneira genérica, como a organização sistemática da Educação, na qual a Educação acontece em instituições escolares e em vários outros ambientes nos quais os conhecimentos são compartilhados.

Libâneo (2002) explicita que a Pedagogia se caracteriza como uma ciência, cujo objeto de estudo é a educação, e por isso é responsável pelo estudo da educação em diversos espaços onde são previstos conhecimentos educativos e pedagógicos. Podemos dizer que, o papel do pedagogo é muito amplo e não se restringe apenas ao trabalho escolar, onde pode exercer a docência. Torna-se essencial pensar a educação em seus processos formativos e entender as várias formas e manifestações educacionais que contribuem para o processo de ensino e aprendizagem dos sujeitos.

A educação não está limitada somente a um espaço físico, ela ocorre em todos os momentos de nossas vidas, em todos os espaços, sendo esses escolares ou não escolares. Como dispõe no art. $1^{\circ}$ da Lei de Diretrizes e Bases da Educação Nacional (LDB) "a educação abrange os processos formativos que se desenvolvem na vida familiar, na convivência humana, no trabalho, nas instituições de ensino e pesquisa, nos movimentos sociais e organizações da sociedade civil e nas manifestações culturais".

Corroborando, com a afirmativa Cofferri e Nogaro (2010), apontam que a Pedagogia não determina em qual espaço ou direção devem ocorrer os processos educativos, visto que a educação não ocorre isoladamente podendo acontecer em outros espaços a partir das relações sociais. Logo, para os autores o pedagogo possui em sua formação habilidades e saberes que vão muito além da docência, tendo uma atuação ampla desenvolvendo práticas pedagógicas que contribuam para a formação humana e construção da cidadania.

Durante a disciplina "Estratégias de ensino e aprendizagem" ofertada no curso de mobilidade internacional "on-line" ofertada em parceria com o Programa de Pós-graduação em Educação Matemática da UFOP e o Programa de Mestrado em Educação com ênfase em Pedagogia Universitária da Universidade Nacional da Costa Rica, foi possível compreender os aspectos políticos que 
perpassam o universo da organização universitária em uma perspectiva pedagógica, além de também fornecer conhecimentos teóricos a respeito da prática docente e do papel do professor universitário.

O presente artigo tem como objetivo discutir os formatos de práticas pedagógicas possíveis de serem aplicados em uma disciplina do curso de Pedagogia, mais especificamente, a disciplina de Introdução à educação, para tanto nas seções seguintes estão descritos o procedimento metodológico de construção deste trabalho e o contexto do curso de Pedagogia no Brasil. Neste trabalho concentramos nossos esforços no currículo do Curso de Pedagogia da Universidade Federal de Ouro Preto; deste modo serão apresentados o Instituto e o Departamento de ensino no qual o curso de Pedagogia está inserido, a matriz curricular do curso e o contexto no qual a disciplina de Introdução a educação se insere nesse.

Após as discussões contextualizadoras do nosso objeto de pesquisa, estão apresentadas possíveis estratégias que podem ser aplicadas nessa disciplina de acordo com a ementa disponibilizada publicamente no "site" da instituição. Escolher esta disciplina como objeto de análise se justifica a partir do seguinte aspecto: é uma disciplina cujo próprio nome sugere ser a porta de entrada para as discussões do campo educacional permitindo a compreensão do papel que a Pedagogia assume perante a Educação.

\section{METODOLOGIA}

Para o desenvolvimento deste artigo ressaltamos a seguir os procedimentos metodológicos que nos permitiram alcançar os resultados da pesquisa realizada. A produção desenvolveu-se a partir de dois enfoques: primeiro uma contextualização geral, na qual é abordada a Instituição que oferece o curso de Pedagogia e, em seguida é apresentada a sua matriz curricular e, por fim, apresentamos a disciplina a ser analisada. $\mathrm{O}$ outro enfoque diz respeito à práticas pedagógicas possíveis de serem realizadas na disciplina.

Esta produção busca se encarregar da análise curricular do curso de Pedagogia, concentrando esforços em uma disciplina específica, Introdução à Educação, oferecida no $1^{0}$ período, no âmbito de uma Instituição de Ensino Superior Pública Federal. Neste texto são destacadas algumas estratégias de ensino e aprendizagem de acordo com o contexto no qual a disciplina se insere: na perspectiva de trabalho educacional, cujo objeto de análise é uma disciplina pensada a partir de uma organização educacional, em curso de formação de profissionais da Educação em uma instituição de Ensino Superior. Deste modo a presente produção foi elaborada a partir da abordagem de metodologia qualitativa, na qual serão apropriados conhecimentos científicos para sustentar a discussão.

\section{CONTEXTUALIZAÇÃO DO CURSO DE PEDAGOGIA NO BRASIL}

Torna-se de suma importância traçar uma breve trajetória do curso de Pedagogia no Brasil, paralelamente ao processo de construção da identidade do pedagogo. Desde 1939, quando o curso foi criado no Brasil, muitos foram os estudos, reformulações, e inovações realizados sobre o curso de Pedagogia e os cursos de Formação de professores. Ao longo da sua história, o curso de Pedagogia teve como objeto de estudos e objetivos essenciais os processos educativos, tanto nas instituições escolares, quanto em outros ambientes, voltados essencialmente à educação de crianças nos anos iniciais de escolarização (BRITO, 2006, p. 01). 
Podemos citar, cinco períodos históricos da trajetória do curso de Pedagogia: o 10 período aborda sua criação em 1939; $2^{\circ}$ as alterações advindas do Parecer CFE n. 251/62; o 30 relaciona-se à Reforma Universitária de 1968 ( Lei n 5.540 de 28 de novembro), especificamente, no artigo 30, que definia as habilitações dos especialistas que atuariam nos sistemas de ensino, desenvolvendo funções de Administração, Planejamento, Inspeção, Supervisão e Orientação; o 40 Refere-se às discussões e debates da década de 1980 acerca dos rumos do curso de Pedagogia ; e por último o 50 atém-se à década de 1990, com a reforma educacional e as propostas das Comissões de Especialistas de Pedagogia e a aprovação das novas Diretrizes Curriculares Nacionais para o Curso de Pedagogia.

A iniciativa da implantação e implementação do Curso de Licenciatura em Pedagogia ocorreu frente às alterações propostas pela Resolução CNE/CP No 1/2006, que institui as Diretrizes Curriculares Nacionais para essa licenciatura. Desta maneira, frente às novas orientações postuladas, tornou-se necessária a implementação de uma proposta pedagógica para o Curso de Licenciatura em Pedagogia que contemplasse e incluísse aspectos apontados na Resolução CNE/CP de 05/2006. Tais diretrizes curriculares deixam claro que a identidade do curso de Pedagogia deve ser pautada pela na docência, implicando a licenciatura como identidade essencial do pedagogo. Por ter uma formação mais abrangente, o pedagogo ainda continua sendo formado para atuar em espaços escolares, dentro e fora da sala de aula, e também em outros espaços onde se fizer necessária a sua presença. Sua importância se faz notória por meio da formação integral, apropriada de campos de conhecimento como História, Psicologia, Sociologia, Filosofia e Política que preparam este profissional para atuar na escola tal qual está posta hoje: diversificada. Outra questão ressaltada nas diretrizes é a reafirmação das universidades como lócus privilegiado de formação de professores, que abordaremos a seguir.

\subsection{INSTITUTO DE CIÊNCIAS HUMANAS E SOCIAIS E O CURSO DE PEDAGOGIA DA UFOP}

A Universidade Federal de Ouro Preto (UFOP) foi instituída em Ouro Preto, Minas Gerais, como Fundação de Direito Público em 21 de agosto de 1969, incorporando duas instituições de ensino superior centenárias: a Escola de Farmácia (1839) e a Escola de Minas (1876). Atualmente, oferece 51 cursos de graduação, sendo 47 presenciais e quatro a distância. Quanto à Pós-graduação, são oferecidos 24 cursos de Mestrado acadêmico e oito profissionais, 15 opções de Doutorado e 10 especializações.

A UFOP possui três campi de ensino presencial nas cidades de Ouro Preto, Mariana e João Monlevade. O Instituto de Ciências Humanas e Sociais - ICHS, terceira unidade acadêmica da UFOP, está situado na cidade de Mariana (MG) e oferece, na atualidade, as graduações em História, Letras e Pedagogia, em cursos de licenciatura e bacharelado; cursos de Pós-graduação Stricto Sensunas áreas de História, Letras e Educação. O ICHS, além do trabalho de ensino e pesquisa, sempre buscou transcender seus limites internos e atuar junto à comunidade externa, através da oferta de cursos e projetos de extensão e outras modalidades de divulgação de saberes. O curso de Pedagogia da UFOP, foi criado no ano de 2008 e situa-se no Campus da cidade Mariana-MG, no ICHS. Oferece 40 vagas por período, nos turnos vespertino e noturno. Destina-se à formação de professores para exercer funções de magistério na Educação Infantil e nos anos iniciais do Ensino Fundamental, nos cursos de Ensino Médio, na modalidade Normal; função de Educação Profissional na área de serviços, em apoio escolar e em outras áreas nas quais sejam previstos conhecimentos pedagógicos. 


\subsection{MATRIZ CURRICULAR DO CURSO DE PEDAGOGIA}

De acordo com a Resolução do CNE/ CP no 1, de 15 de Maio de 2006 e conforme artigo 13 da Resolução no 2 de 1 de julho de 2015, o Curso de Licenciatura em Pedagogia possui carga horária mínima de 3200 horas mínimas de efetivo trabalho acadêmico, assim distribuídas: no mínimo, 3.200 (três mil e duzentas) horas de efetivo trabalho acadêmico, em cursos com duração de, no mínimo, 8 (oito) semestres ou 4 (quatro) anos, como mostra no Quadro 1.

Quadro 1. Dados gerais do Curso Pedagogia da UFOP

\begin{tabular}{|c|c|}
\hline NOME DO CURSO & Curso de Licenciatura em Pedagogia \\
\hline Área do conhecimento & Humanas \\
\hline Titulação conferida & Licenciado em Pedagogia \\
\hline Nível & Superior \\
\hline Modalidade & Presencial \\
\hline Grau Acadêmico & Licenciatura \\
\hline Duração & 4 anos / 8 semestres \\
\hline Regime escolar & Semestral \\
\hline Forma de ingresso & $\begin{array}{l}\text { A seleção é feita exclusivamente pela nota do Exame } \\
\text { Nacional do Ensino Médio (Enem) mediante do sistema } \\
\text { informatizado do Ministério da Educação-SISU. }\end{array}$ \\
\hline Número de vagas anuais & 50 vagas- Vespertino e Noturno \\
\hline Regime de matrícula & Semestral \\
\hline Prazo de integralização Mínimo & 8 semestres ( 4 anos) \\
\hline $\begin{array}{l}\text { Carga Horária de Atividades } \\
\text { acadêmico-científico culturais - } \\
\text { ATV100 }\end{array}$ & $200 \mathrm{~h}$ \\
\hline $\begin{array}{l}\text { Componentes } \\
\text { Exigidos para Integralização no } \\
\text { Curso }\end{array}$ & $\begin{array}{l}\text { Disciplinas Obrigatórias } 2820 \\
\text { Disciplinas Eletivas } 300 \\
\text { Disciplinas Optativas } 00 \\
\text { Disciplinas Facultativas Atividades } 00 \\
\text { Total: } 3.320 \mathrm{~h}\end{array}$ \\
\hline
\end{tabular}

Fonte: Elaborado pelas autoras, com base na Matriz Curricular do curso de Pedagogia da UFOP,2020.

O curso de Pedagogia da UFOP, contempla duas matrizes curriculares: Pedagogia - Currículo 1 e Currículo 2. A Matriz Curricular, portanto, está estruturada de forma que a integralização de estudos dos alunos aconteça ao longo dos oito semestres letivos. A matriz curricular do curso contém disciplinas voltadas ao ensino dos conteúdos, das metodologias e da prática de ensino. Há também disciplinas dedicadas ao estudo dos fundamentos sociológicos, antropológicos, filosóficos, psicológicos e históricos da Educação. As disciplinas direcionadas ao conhecimento dos sistemas de ensino, das instituições escolares e da sala de aula auxiliam na relação professor-aluno e nos 
problemas educativos atuais. A realização de estágios em espaços educativos escolares e não escolares permite a prática das metodologias estudadas em sala. Nesse sentido podemos afirmar que o curso de pedagogia possui uma multiciplicidade de significados que apontam para um único objetivo, a formação dos futuros profissionais (DÍAZ BARRIGA, 2003). Atualmente o curso de Pedagogia na modalidade presencial não possui um Projeto Pedagógico de Curso (PPC) estabelecido; este ainda está em construção.

\subsection{CONTEXTO NO QUAL A DISCIPLINA INTRODUÇÃO À EDUCAÇÃO SE INSERE NO CURSO DE PEDAGOGIA}

A disciplina Introdução à Educação é oferecida no primeiro semestre do curso de Pedagogia, e tem caráter eminentemente teórico, com carga horária semestral 60 horas que equivale à 72 horas/aula; é obrigatória no currículo do curso de Pedagogia na modalidade licenciatura, e tal disciplina é lecionada atualmente por uma docente. Pelo exposto, a disciplina é voltada para a discussão sobre a Pedagogia: conceito, âmbito de atuação, objeto de estudo, função e relação com a ação educativa; a Pedagogia na formação do educador e na transformação da prática pedagógica; a visão ampla teórica e prática do processo educativo em todas as suas dimensões escolar, institucional, não institucional; e a discussão sobre seus mecanismos, suas potencialidades e seus limites. É composta por três unidades respectivamente: Unidade I - Questões atuais da educação; Unidade II Contextualização da Pedagogia no Brasil; e pôr fim a Unidade III- A formação do pedagogo: perfil e campo profissional.

Quadro 2. Introdução à Educação

\section{Tipo: obrigatória Carga horária semanal: 60 - 72 horas}

EMENTA: Pedagogia: conceito, âmbito de atuação, objeto de estudo, função e relação com a ação educativa. A pedagogia na formação do educador e na transformação da prática pedagógica. Visão ampla -teórica e prática - do processo educativo em todas as suas dimensões - escolar, institucional, não institucional. Discussão sobre seus mecanismos, suas potencialidades e seus limites.

CONTEÚDO PROGRAMÁTICO 1. Introdução 1.1. Conceitos de educação 1.2. Pedagogia e Pedagogia Cultural 1.3. Educação e pedagogia: discussão conceitual 1.4. Uma pequena história da Pedagogia 2. Educação e cultura 2.1. Estudos Culturais e educação 2.2. Raça e etnia 2.3. Gênero e Sexualidade 3. Educação escolar e realidade brasileira 3.1. Possibilidades e limites da educação escolar 3.2. O campo do conhecimento pedagógico e a identidade profissional do pedagogo 3.3. A educação perante os desafios e tensões na sociedade contemporânea.

BIBLIOGRAFIA BRANDÃO, Carlos Rodrigues. O que é Educação. São Paulo: Brasiliense, 2007. (Textos 1 e 5). CARDOSO, Nádia. Movimento negro pós-70. Disponível em: http://www.smec.salvador.ba.gov.br/site/documentos/espaco-

virtual/espacodiversidade/RELA\%C3\%87\%C3\%95ES\%20\%C3\%89TNICAS/WEBARTIGOS/artigo.pdf. Acesso em: 02 set. 2009. (Texto 9) ESTEBAN, Maria Teresa. Educação Popular: Desafio à Democratização da Escola Pública. Cedes, Campinas, v. 27, n. 71, jan./abr. 2007. (Texto 6) CAMBI, Franco. História da pedagogia. São Paulo: UNESP, 1999. (Texto 3) GOHN, Maria da Glória. Educação não-formal, participação da sociedade civil e estruturas colegiadas nas escolas. Ensaio, v. 14, n. 50, jan./mar. 2006. (Textos 2) LOURO, Guacira Lopes. Entrevista: Gênero e Sexualidade. Presença Pedagógica, v.12, n.72, nov./dez. 2006. (Textos 10) MENDES, Cláudio Lúcio. Como os jogos eletrônicos educam? Presença Pedagógica, v. 11, n. 62, mar./abr. 2005. (Texto 12) PARAÍSO, Marlucy Alves. Contribuições dos Estudos Culturais para a Educação. Presença Pedagógica, v. 10, n.55, jan./fev. 2004. (Texto11) PRETI, Oreste. Educação a distância: uma prática educativa mediadora. Disponível em: http://www.dai.cefetma.br/cicero/Ensino/ED/5.pdf. Acesso em: 31 ago. 2009. (Texto 7) SACRISTÁN, José Gimeno. A educação que temos e a educação que queremos. IMBERNÓN, Francisco (Org). A Educação no século XXI. Porto Alegre: Artemed, 2000. (Texto 4) SCHEIBE, Leda; AGUIAR, Márcia A. Formação da educação no Brasil. Educação \& Sociedade, a. XX, n. 68, dez. 1999. (Texto 8).

Fonte: Ementa da disciplina de Introdução à Educação recuperado no dia 06 de novembro de 2020: https://ichs.ufop.br/sites/default/files/ichs/files/4edu500-introduo_a_educao.pdf. 


\section{ESTRATÉGIAS DE ENSINO E APRENDIZAGEM POSSÍVEIS DE SEREM APLICADAS NA DISCIPLINA}

Neste tópico apresentamos algumas estratégias possíveis de serem aplicadas no contexto da disciplina de Introdução à Educação que é uma disciplina de caráter essencialmente teórico; as disciplinas que assumem a posição de teoricidade precisam ser pensadas em um formato à estarem acessíveis aos alunos, visto que esta é uma disciplina obrigatória ofertada no primeiro período do curso.

A palavra estratégia derivada do grego strategía e do latim strategia "significa a arte de aplicar ou explorar os meios e as condições favoráveis e disponíveis, com vista à consecução de objetivos específicos" (ANASTASIOU; ALVES, 2012, p. 75-76). De acordo, com Anastasiou e Alves (2012, p. 77), estratégias de ensino são métodos ou técnicas desenvolvidas para serem utilizadas como meio de impulsionar o ensino e a aprendizagem, sendo o docente considerado o verdadeiro estrategista, no sentido de estudar, selecionar, organizar e propor as melhores ferramentas facilitadoras da aprendizagem. Através delas, ainda, "[...] aplicam-se ou exploram-se meios, modos, jeitos e formas de evidenciar o pensamento, respeitando as condições favoráveis para executar ou fazer algo".

Para Beraza (2011) as estratégias de ensino aprendizagem compõem um território científico de elementos conceituais e destrezas práticas próprias e distintas. Segundo Velasco e González (2008), elas devem ser caracterizadas pela interação equitativa, e por discussões contínuas entre docentes e discentes no que condiz à prática em sala de aula, a fim de propiciar o ensino e aprendizagem; para tanto é de suma importância desenvolver estratégias que promovam a construção efetiva do conhecimento. A prática docente é uma profissão complexa e multirreferencial que implica definir diversos conceitos que permitam ao professor alcançar o objetivo de ensinar os conteúdos aos alunos (ESTRADA; BACA, s.d.). Neste sentido, são vários os tipos de estratégias de ensino e aprendizagem que os docentes podem utilizar em sua prática. Entre eles:

\section{a. Aula expositiva dialogada:}

Aulas expositivas dialogadas consistem em momentos nos quais os professores explicam os conteúdos e os alunos fazem perguntas e tiram suas dúvidas durante a explicação ou ao final dela.

\section{b. Oficinas de Escrita Acadêmica e ABNT}

As oficinas são ações pontuais, normalmente de uma hora, com temáticas específicas como, organização do tempo, projeto de vida, escrita acadêmica, anotações em sala de aula, fichamentos, normas ABNT, que apresentam como finalidade aperfeiçoar a escrita de textos acadêmicos, desde sua elaboração até sua normalização.

Logo, faz se necessário abordar procedimentos de leitura de textos acadêmicos e apresentação das normas da ABNT para citação, referências bibliográficas e formatação de textos, e além disto discutir questões relacionadas ao plágio. Tal oficina constitui-se de extrema importância, uma vez que visa aprimorar a qualidade dos textos acadêmicos produzidos, visando aperfeiçoar a formação acadêmicocientífica de estudantes da UFOP do $1^{0}$ período do curso de Pedagogia, habilitando-os(as) como leitores(as) e produtores(as) dos principais gêneros acadêmicos e suas configurações formais e semânticas: resumo, resenha, artigo, monografia, projeto de pesquisa, relatórios de pesquisa, dissertação e tese. 


\section{c. Ficha de Leitura:}

As fichas de leitura proporcionam aos alunos explorarem, de forma crítica, as ideias expressas em diversos tipos de textos atentando-se para o contexto, a temática, a interpretação, a problematização e futuramente a síntese do conteúdo.

\section{d. Fichamento de textos:}

Os fichamentos são uma estratégia de aprendizagem que pode ser desenvolvida pelos alunos com o intuito de assimilar os conteúdos de um texto. Eles consistem no destaque de trechos que os leitores consideram importantes e que podem ser utilizados como citações em trabalhos futuros.

\section{e. Mapa conceitual:}

Na concepção de Santos (2008) o mapa conceitual se coloca como um instrumento adequado para estruturar o conhecimento que está sendo construído pelo aprendiz, pois oportuniza ao estudante aprender a aprender perfazendo reflexões e conceitos sobre um determinado tema, um exemplo seria a construção de um diagrama que relaciona os mais variados assuntos por meio de conceitos-chave.

\section{f. Estudo dirigido:}

O estudo dirigido pode ser um grande aliado para trabalhar os conteúdos disciplinares, seja de forma individual ou grupal, visando sanar dificuldades no processo de ensino e aprendizagem. Com as tecnologias digitais e a infinidade de recursos disponíveis e gratuitos, as possibilidades didáticas para esse tipo de metodologia se multiplicaram; tal estratégia aliada a recursos e tecnologias integradas aos ambientes virtuais de aprendizagem como o Moodle, um Ambiente Virtual de Aprendizagem (AVA) integrado ao SISCAD e SIGPOS, e o Google Classroom, uma sala de aula virtual que permite o gerenciamento de atividades, "feedback" e compartilhamento de conteúdo, links, vídeos e muito mais. Ele permite integração com todas as ferramentas do Google For Education: Documentos, Slides, Planilhas, Formulários, Drive, Meet, etc.

De acordo com Libâneo (2017) o estudo dirigido se encaixa nas estratégias de ensino e aprendizagem metodológicas do estudo ativo, que hoje chamamos de metodologias ativas, ou seja, que focalizam a resolução de problemas contextuais relacionados aos conteúdos que estão sendo estudados na disciplina. Deste modo, uma das finalidades do estudo dirigido "[...] é a proposição de questões que os alunos possam resolver criativamente, de modo que assimilem o processo de busca de soluções de problemas" (LIBÂNEO, 2017, p. 3044). Logo, o estudo dirigido é uma técnica que compreende a elaboração de um roteiro de estudo para que os estudantes executem as etapas definidas de forma sistemática e organizada, de maneira que possam compreender, interpretar, analisar, avaliar e criar/aplicar o conteúdo abordado no roteiro proposto.

\section{g. Atividades em dupla}

As atividades em dupla proporcionam o compartilhamento de conhecimentos entre dois alunos, e nessas atividades os alunos são livres para se organizarem e criarem suas próprias estratégias de realização de atividades. 


\section{h. Seminários em grupo:}

Consiste na apresentação de um trabalho realizado pelos alunos após consulta de fontes diversas. 0 seminário, como estratégia de ensino e aprendizagem é eficaz, pois estimula a relação interpessoal e dinamiza o processo de aquisição de novos conhecimentos.

\section{i. Aprendizagem baseada em atividades extracurriculares}

Freire (1996), explicita que a formação docente deve causar a indagação do educador, desafiando-o a aprimorar-se de técnicas de saberes que são necessários à atuação da prática educativa. Deste modo, é essencial a busca por recursos que permitam adquirir novas práticas, aprender a pesquisar, um aprendizado contínuo, que permita uma melhor qualificação no exercício de sua função. "É preciso que, na formação permanente dos professores, o momento fundamental é o da reflexão crítica sobre a prática, de maneira que se pense na prática de hoje ou de ontem para melhorar a próxima" (FREIRE, 1996, p.44).

No caso desta estratégia, pretende-se a organização de eventos como um "Ciclo de pedagogos" cuja a temática engloba "A formação do pedagogo: perfil e campo profissional", no âmbito da disciplina, em parcerias com Projetos; um exemplo é Programa de Educação Tutorial - PET-Pedagogia. Tal atividade é de extrema importância para os alunos do $1^{\circ}$ período do curso de Pedagogia, visto que se propõe apresentar profissionais que atuam em diversas áreas da Educação, bem como possibilitar que os discentes conheçam os diferentes espaços de atuação do pedagogo e conheçam melhor o campo amplo de atuação profissional do Pedagogo. Outra estratégia de ensino relevante, são os Minicursos voltados para os discentes do $1^{\circ}$ período; um exemplo é a apresentação de Plataformas, como a Plataforma Lattes, de extrema importância no contexto científico nacional e internacional. 0 foco no preenchimento do Currículo Lattes, é uma atividade que pode ser realizada no laboratório de informática (LCC) e constitui-se na apresentação da Plataforma Lattes e orientação dos participantes sobre o cadastro, preenchimento de atualizações e publicação do currículo lattes.

\section{j. Gameficação}

Gameficação da sala de aula consiste em uma estratégia de ensino na qual o professor planeja a sua aula pensando na perspectiva de games, seja utilizando instrumentos digitais ou não.

\section{CONSIDERAÇÕES FINAIS}

Podemos concluir que a disciplina de Introdução à Educação é um componente curricular necessário ao curso de Pedagogia, pois proporciona aos estudantes universitários um entendimento do campo da Educação de maneira geral, sobretudo quando se considera a Educação como uma ciência. A pedagogia se insere no campo educacional de maneira muito presente, principalmente no que tange a organização do conhecimento e dos procedimentos necessários a aquisição a assimilação de conhecimentos. As estratégias de ensino e aprendizagem aplicadas pelos professores propiciam o desenvolvimento de estratégias de aprendizagem criadas pelos próprios alunos.

A disciplina de Introdução à Educação assume um caráter completamente teórico e por vezes histórico, pois é importante proporcionar aos estudantes o conhecimento do que é Educação, de onde e com qual finalidade ela surge; além de mostrar aos alunos como a Educação se relaciona com a Pedagogia. Claro que as possíveis discussões não estão nulas em questões ideológicas, pois a 
Educação e a Pedagogia têm sido analisadas ao longo dos anos de diversas maneiras e ao passo que alguns pesquisadores consideram e defendem a Educação como ciência outros pesquisadores não. Nessa perspectiva o formato a ser seguido pelo professor que irá lecionar a disciplina reflete muito da identidade profissional deste.

Desde o ingresso do estudante no curso de licenciatura em Pedagogia é necessário que o processo de ensino e aprendizagem seja estimulado a partir de estratégias de ensino e metodologias diversificadas, a fim de que estes possam ter um olhar crítico ao contexto educacional, bem como assimilar novos conhecimentos. Dessa maneira, o professor deve estar convencido "[...] de que ensinar não é transferir conhecimento, mas criar possibilidades para a sua produção ou a sua construção" (FREIRE, 1996, p. 22).

Em suma, este artigo apresentou estratégias de ensino e aprendizagem relevantes não apenas para a aprendizagem dos estudantes do curso de Pedagogia, mas também como uma importante ferramenta e parâmetro para a atuação dos docentes universitários quanto ao uso de estratégias de ensino e aprendizagem. Portanto, as discussões aqui apresentadas sobre as estratégias de ensino e aprendizagem possíveis de serem aplicadas, na disciplina Introdução à Educação do $1^{0}$ do curso de Pedagogia da UFOP, não findam nossa discussão acerca das estratégias de ensino e aprendizagem eficazes no cotidiano universitário, mas emergem como tentativa de se depreender proposições que possam nortear tais práticas de ensino.

\section{REFERÊNCIAS}

ANASTASIOU, Léa das Graças Camargos; ALVES, Leonir Pessate. (Orgs.). Processos de Ensinagem na Universidade: pressupostos para as estratégias de trabalho em aula. 10. ed. Joinville, SC: Univille,2012. 145 p.

BRASIL. Conselho Nacional de Educação. Resolução CNE/CP 1/2006. Institui Diretrizes Curriculares Nacionais para o Curso de Graduação em Pedagogia, licenciatura,2006. Disponível em: Recuperado no dia 01 de novembro de 2020 em:

http://portal.mec.gov.br/cne/arquivos/pdf/rcp01_06.pdf.Acesso em: 01 de nov.2020.

BERAZA, Miguel Zabalza. Nuevos enfoques para la didáctica universitaria actual. Perspectiva, Florianópolis, v.29, n.2, p.387-416, jul./dez.2011.

BRITO, Rosa Mendonça de. Breve Histórico do Curso de Pedagogia no Brasil. Revista eletrônica da Faculdade de Educação da Universidade Federal do Amazonas-FACED, v.1, n.1,2006.

COFFERRI, Fernanda Fátima; NOGARO, Arnaldo. Competências do Pedagogo como Educador Social: promovendo o desenvolvimento psicossocial do ser humano. Perspectiva Erechim, v.34 n.128, p. 7-21,2010.

DÍAZ-BARRIGA, Ángel. Currículum. Tensiones conceptuales y prácticas. Revista Electrónica de Investigación Educativa, México: Mc Graw-Hill, v. 5, n.2,2003.

ESTRADA, Ortega Federico; BACA, Velia Terrazas. Estratégias didáticas associadas à aprendizagem baseada em competência em uma instituição de ensino superior. Trabalho apresentado no XI Congresso Nacional de Pesquisa Educacional/ 14. [online]. Prácticas Educativas en Espacios Escolares / Ponencia, n.d. Disponível em: 
http://www.comie.org.mx/congreso/memoriaelectronica/v11/docs/area_14/1434.pdf. Acesso em: 01 de nov.2020.

FREIRE, Paulo. Pedagogia da autonomia: saberes necessários à prática educativa. São Paulo: Editora Paz e Terra, 1996.

LIBÂNEO, José Carlos. Ainda as perguntas: o que é pedagogia, quem é o pedagogo, o que deve ser o curso de pedagogia. Em: Pimenta, S. G. (Org.). Pedagogia e pedagogos: caminhos e perspectivas. São Paulo: Cortez,2002.

LIBÂNEO, José Carlos. Didática. São Paulo: Cortez,2017.

SANTOS, Júlio César Furtado dos. Aprendizagem significativa: modalidades de aprendizagem e o papel do professor. Porto Alegre: Mediação,2008.

VELASCO, Antônio José; GONZÁLEZ, Leonor Alonso de. Sobre a teoria da educação dialógica. Educere, v.12, n.42, Meridade,2008. 